\title{
LA FUNCIÓN DE LA CARTA DE INTENCIONES EN LA INTERPRETACIÓN DE LOS CONTRATOS CELEBRADOS POR LA EMPRESA
}

\author{
Silvia Gema Navares González. \\ Universidad Carlos III de Madrid, Jefe de Área de Cooperación Internacional y Relaciones con los Tribunales. \\ Oficina Española de Patentes y Marcas, España \\ E-mail: silvia.navares@oepm.es
}

\begin{abstract}
Resumen
La interpretación de los contratos celebrados por las empresas plantea dificultades distintas de las que se producen respecto de los contratos celebrados por personas físicas. La peculiaridad de la función interpretadora en este campo radica en que el objeto de los mismos es, o puede ser, al mismo tiempo el sujeto que celebra el contrato. La empresa, como ente, puede así proceder a la venta de sus activos, en su totalidad o en una parte, confundiéndose de este modo como se ha señalado, el sujeto con el objeto del contrato. Este trabajo tiene por objeto el estudio de las conocidas como "cartas de intenciones" - "letter of intent"documentos que fijan las bases para la negociación y primera propuesta sobre la celebración futura de un contrato por la empresa, así como su función y alcance para la interpretación de los contratos celebrados por aquélla.
\end{abstract}

Palabras clave: Interpretación de los contratos, Carta de intenciones, Empresa, Precontrato.

\begin{abstract}
To accomplish the objective of the strategy of Lisbon, decreed in the two thousand, the EU adopted, through the commission of January the two thousand and four a "proposal of Directive related to the services in the domestic market", also known as Directive "services", impelled by the European commissioner of Domestic market, Frits Bolkestein. After many arguments, at least the Directive of services has come to mean a fundamental step in the effective accomplishment of the foreseen objectives to the getting of the sole domestic European market. The work analyzes how the transposition of the Directive of services to the Judicial Spanish regulation and how the actual Spanish rules were modified in objective matters of the Directive.
\end{abstract}

Key Words: Directive of services, European Union, sole European Market, Free circulation of services

Résumé

L'interprétation des contrats conclus par des entreprises pose des défis différents de ceux qui se produisent sur les contrats conclus par des personnes physiques. La particularité de la fonction-interprétation dans ce domaine est que l'objet des présentes est ou peut être, le sujet, tout en concluant le contrat. La société, comme une entité, peut alors procéder à la vente de ses actifs, en tout ou en partie, ce qui comme on l'a confondu, l'objet du contrat. Ce travail vise à étudier connu sous le nom des "lettres d'intention" - "lettre d'intention", des documents qui établissent la base pour la négociation et la conclusion de la première proposition sur l'avenir d'un contrat par la société, sa fonction et marge d'interprétation des contrats conclus par celle-ci.

Mots-clés: Interprétation des contrats, lettre d'intention, l'entreprise, contrat antérieur. 

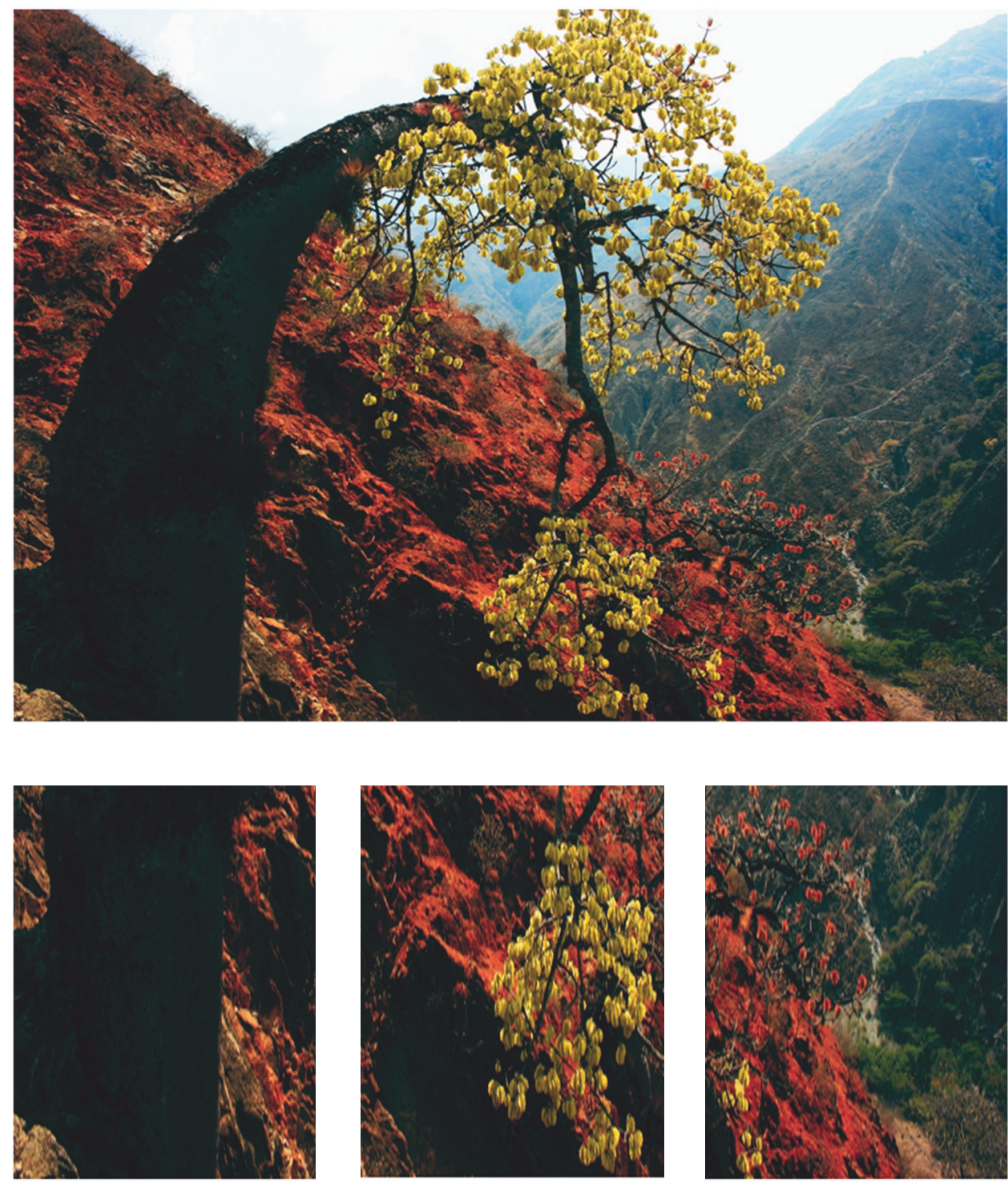

Cañón del Chicamocha - Ceibas Barrigonas

Jorge William Sánchez Latorre 


\section{LA FUNCIÓN DE LA CARTA DE INTENCIONES EN LA INTERPRETACIÓN DE LOS CONTRATOS CELEBRADOS POR LA EMPRESA*}

Silvia Gema Navares González

\section{INTRODUCCIÓN}

Este trabajo tiene por objeto el estudio de las conocidas como "cartas de intenciones" y su incidencia en el campo de la interpretación de los contratos celebrados por la empresa. La peculiaridad de la función interpretadora en este campo radica en que el objeto de los mismos es, o puede ser, al mismo tiempo el sujeto que celebra el contrato. La empresa, como ente, puede así proceder a la venta de sus activos, en su totalidad o en una parte, confundiéndose de este modo como se ha señalado, el sujeto con el objeto del contrato.

Evidentemente en la celebración de este tipo de contratos no hay una intención en sentido estricto o, al menos, en el sentido que se le da en el caso de contratos celebrados por personas físicas. No existe aquí un sujeto con conciencia e intención contractual que pueda ser deducida por las reglas tradicionales de interpretación de los contratos. Es por ello por lo que se debe acudir a instrumentos auxiliares de la interpretación entre los que, en los casos de contratos celebrados por las empresas, tienen una importancia fundamental las llamadas cartas de intenciones - "letter of intent”- documentos que fijan las bases para la negociación y primera propuesta sobre la celebración futura de un contrato, que permite así que se empiecen a llevar a cabo las actuaciones que desembocarán en la firma del mismo. Son precisamente estas actuaciones basadas en la carta de intenciones, más que la propia firma del contrato, las que pueden provocar dificultades en caso de divergencias con la voluntad contractual.

\footnotetext{
* El artículo reflexiona sobre la función e incidencia que cumple la carta de intenciones en la interpretación de los contratos celebrados por la empresa, a partir de las investigaciones que adelanto la autora sobre la temática, y su incidencia en la actividad empresarial en el marco de la garantía de la seguridad jurídica.
} 
Las posibles acepciones del término "carta de intenciones" (o letter of intent como es conocida en Derecho Anglosajón) no se agotan aquí. En el ámbito del Common Law, el término letter of intent hace referencia a toda clase de documentos precontractuales, dentro de los cuales se engloban: los documentos que plasman una invitación a negociar (que serían lo que en este trabajo se denominan como carta de intenciones propiamente dicha y que son aquellos a los que se ha hecho referencia en el párrafo anterior), los documentos que reflejan los tratos preliminares llevados a cabo por las partes, es decir, unos documentos bilaterales que contienen el estado de las negociaciones ${ }^{1}$ (que se llamarán pactos de intenciones) y, finalmente, los acuerdos preliminares vinculantes, es decir, los precontratos.

Los problemas de interpretación de los contratos respecto de los cuales se ha firmado una previa carta de intenciones pueden ser muy variados, Por ejemplo, las expresiones y términos contenidos en una carta de intenciones propiamente dicha no son siempre compatibles con los términos utilizados en el contrato que posteriormente se celebre, con lo que la discusión puede surgir a posteriori, una vez firmado aquel, sobre el alcance de las expresiones utilizadas en el mismo. Tampoco es desconocido el hecho de que, en ocasiones, todos los posibles objetivos a conseguir se concluyen con la simple suscripción de la carta de intenciones sin que se produzca la firma de un contrato final. Aquí, de nuevo surgen los problemas, especialmente en los supuestos en que se plantee alguna duda sobre si, en este caso concreto, existe o no acuerdo contractual, de qué tipo y cuáles serían los documentos que deberían tenerse en cuenta. Por otro lado, también son frecuentes los supuestos de que la propuesta inicial de la parte que inicia las negociaciones se haya referido a determinadas cualidades del objeto del futuro contrato; la carta de intenciones no se refiere expresamente a dichas cualidades pero la intención de esa parte es insistir en esas condiciones originales del contrato. La otra parte, sin embargo, actúa de acuerdo a la versión de las condiciones incluida en la carta de intenciones. Posteriormente, las partes fracasarán en sus intentos de acuerdo sobre los términos del contrato y se planteará el problema de si existe o no vínculo obligatorio sobre la base de las conversaciones previas.

Estos problemas pueden ser evitados de diversas maneras. En primer lugar, si la carta de intenciones establece que la intención de las partes es meramente celebrar en el futuro un contrato, dejará claro que entre las partes no ha surgido ni surgirá en el futuro ningún tipo de vínculo, al menos con base exclusivamente en esa carta de intenciones. Por tanto, en relación al primero de los problemas apuntados, si existe algún tipo de discrepancia entre los términos utilizados en la carta y los utilizados en el contrato, siempre prevalecerá el sentido propio de los términos utilizados en este último.

1 En ellos se suelen indicar los puntos sobre los que se ha llegado a un acuerdo y en qué términos, así como que el asunto está en fase de negociación y, por tanto, es imperfecto e inejecutable. Tales indicaciones " se utilizan para negar eficacia contractual a un acuerdo y para indicar que las partes no quedarán vinculadas hasta que se produzca el contrato formal” Treitel G.H. The Law of contract, London, $9^{\mathrm{a}}$ ed., 1995 
Así, en los casos en que ello se considere necesario para evitar imprecisiones en el futuro tanto por discrepancias terminológicas como por divergencias en el contenido, la carta de intenciones puede (debería) fijar dos postulados fundamentales. Primero, es conveniente señalar expresamente que la intención de los contratantes es, no sólo celebrar el contrato en el futuro, sino también clarificar los términos de dicho contrato. De esta manera, se deja claro que la carta de intenciones no constituye en sí misma un acuerdo contractual, y sólo servirá de base y como elemento interpretativo del contrato que se celebre en su día. Para facilitar dicha interpretación se pueden establecer referencias, por ejemplo, a la correspondencia y documentos que deberán ser incorporados con carácter necesario al contrato; también se puede hacer mención del precio pactado así como otros extremos fundamentales.

Por otro lado, los trabajos -que no acuerdos- que empiezan a desarrollarse tras la carta de intenciones y que concluirán, en su caso, con la firma del contrato, deben definirse por referencia a dos parámetros fundamentales: el precio y el tiempo máximo durante el cual podrán desarrollarse dichos trabajos. Esos parámetros permitirán dejar claro que, si el contrato es firmado dentro de un cierto periodo de tiempo especificado por las partes, los acuerdos y precisiones a que se haya llegado durante ese tiempo serán consideradas parte del contrato. Si, por otro lado, el contrato no llega a firmarse, la única obligación será la de pagar el trabajo realizado a la parte que lo haya llevado a cabo, de acuerdo a los términos de la propia carta de intenciones.

Resumido lo anterior, debe realizarse una clara distinción entre el contrato, precontrato y la carta de intenciones, la carta de intenciones es una especie de trato o tanteo preliminar en que, sin naturaleza de precontrato, las partes intercambian opiniones y formulan acuerdos parciales sobre algunos extremos de la negociación, para perfilar así el acuerdo de bases sobre el que se desenvolverá posteriormente el contrato $^{2}$ con términos claramente definidos en el mismo.

En este acuerdo de bases se fijan posiciones, se transmiten deseos, se efectúan propuestas. Esto es, a través de estos tratos previos se planifica el futuro contrato, intercambiándose las intenciones de los contratantes en relación al mismo, sin que ello signifique una vinculación contractual. El alcance de la carta de intenciones es normalmente muy limitado circunscribiéndose su objetivo a contribuir a la mejor articulación de la relación jurídica negocial ${ }^{3}$, sin que en ningún caso su existencia genere una fase contractual previa a partir de la cual se produzca la conclusión del contrato principal.

2 Ya a principios del siglo XX S. Moro, en "El precontrato" en RCDI (1934), negaba todo tipo de eficacia obligatoria alguna en estos tratos o conversaciones preparatorias de un contrato.

3 La jurisprudencia se ha referido a la carta de intenciones señalando que su objetivo es, meramente, que con ella, las futuras partes contractuales, normalmente las empresas, tomen contacto. SSTS 4 de julio de 1991, de 19 de julio de 1994 y de 3 de junio de 1998 entre otras 


\section{LOS CONTRATOS CELEBRADOS POR LA EMPRESA: PECULIARIDADES Y PROBLEMÁTICA DE SU INTERPRETACIÓN}

Las aproximaciones a la interpretación de los contratos celebrados por la empresa pueden ser realizadas desde distintos puntos de vista, de los cuales no es la menos importante la aproximación subjetiva ya mencionada. Efectivamente, para llevar a cabo un adecuado estudio de las pautas interpretativas de tales contratos se debe, ante todo, partir de una cuestión que no es baladí: ¿Qué es una empresa? $\mathrm{Ni}$ el Código de Comercio ni el resto de textos legales del ordenamiento jurídico español, ni de la práctica totalidad de legislaciones de América Latina contienen disposiciones que establezcan taxativamente qué sea lo que se deba entender por empresa ${ }^{4} 5$. Únicamente las Leyes mercantiles más modernas y de forma incipiente y fragmentaria, fijan una serie de características estructurales y funcionales de la empresa que se corresponden con el modelo institucional-normativo que establece las Constituciones y con el concepto económico al que nos referiremos posteriormente.

Como muestra de lo anteriormente señalado, la Ley 27/1992, del 24 de noviembre, de Puertos del Estado y Marina Mercante define la empresa naviera como (Art. 9)

"la persona física o jurídica que, utilizando buques mercantes propios o ajenos, se dedique a la explotación de los mismos, aún cuando ello no constituya su actividad principal, bajo cualquier modalidad admitida por los usos internacionales".

Por su parte, la Ley 16/1987 de Ordenación de los transportes terrestres concibe a la empresa de transportes terrestres como una organización económica y socialmente eficiente que, dotada de autonomía económica y libertad de gestión empresarial, ejerce su actividad sometida a los principios de economía de mercado y libre competencia y con vistas a la obtención de beneficios y a la satisfacción eficaz de las necesidades sociales ${ }^{6}$. Por último, según la Ley 1/1994, de 11 de marzo, sobre

4 A lo sumo, menciones sobre el régimen jurídico aplicable a determinadas situaciones que pueden afectar a la empresa, como pueden ser las normas del Código Civil sobre ganancialidad de ésta, partición de la herencia cuando forma parte del caudal relicto alguna empresa etc. Por otro lado, deben recordarse los principios constitucionales sobre libertad de empresa o economicidad de la misma.

5 Tampoco los ordenamientos jurídicos de América Latina ni el Derecho Andino la definen. Efectivamente, el Derecho Andino no ha tomado en cuenta la diferencia que hay entre Empresa y Empresario y, además como alguna legislación del derecho comparado, confunde el concepto de Empresa con la figura jurídica de Sociedad y Compañía. En el Derecho Ecuatoriano por ejemplo entre otros de América Latina, el empresario no ha sido definido; pero siendo la empresa la sucesión de actos de comercio, quien los ejecute será comerciante conforme el Art.2 de la Ley de Compañías, reconociéndole a éstas la personalidad jurídica con las atribuciones del Código Civil. 
el régimen jurídico de las Sociedades de Garantía Recíproca, la empresa es una unidad productiva socialmente valiosa que combina capital y trabajo y de la que es titular un sujeto llamado empresario que desarrolla a través de la empresa una o varias actividades de naturaleza económica y sobre la base de una sede física o establecimiento ${ }^{7}$ (normalmente $^{8}$ ).

Poco se puede deducir de estas definiciones, aunque de ellas sí que se pueden extraer, como primera aproximación, tres de las notas fundamentales que caracterizan a cualquier empresa, esta puede ser desarrollada por personas físicas o jurídicas que toda empresa desarrolla por el hecho mismo de ser empresa, algún tipo de actividad organizada en el tráfico jurídico-económico y que esa actividad va a consistir básicamente en una "explotación", es decir, en una tarea consistente en la obtención de algún tipo de beneficio de una realidad económica existente para satisfacer las necesidades sociales.

No vamos a entrar aquí en las distintas teorías sobre la naturaleza jurídica de la empresa que, a partir de éstas y otras características y de explicaciones más o menos rigurosas acerca del substrato que fundamenta aquélla, pretenden construir el régimen jurídico que debería serle aplicado. Cualquier concepto jurídico de empresa, si pretende ser mínimamente realista, debe partir del concepto económico9. Así lo han hecho algunas Sentencias del Tribunal Supremo en que se define a la empresa como

"unidad socioeconómica de producción" (SsTS de 26 de enero y 3 de marzo de 1987 -RJ 292 y 767 respectivamente-) o como "organización de medios personales y materiales encaminada a la realización de la actividad que constituye su objeto" (SsTS de 9 de julio de 1987 y de 26 de enero de 1988 - RJ5123 y RJ 56 respectivamente-).

En cualquier caso, las definiciones anteriormente apuntadas no explican una realidad extraña que concurre en la empresa y que hace que ésta sea al tiempo objeto y sujeto de derechos a la vez que forma de organización. Efectivamente, resulta anómalo que un ente que puede ser comprado, vendido, arrendado, es decir, ser objeto de los más variados negocios jurídicos, pueda él mismo ser sujeto de un contrato de compraventa, arrendamiento u otros. Al mismo tiempo resulta anómalo que la empresa en cuanto objeto, para ser considerada verdaderamente como empresa,

$7 \quad$ Vid. Artículos $1.1,2.1,6,17,18$ y 24

8 Decimos normalmente, porque últimamente algunas Leyes mercantiles reconocen la posibilidad de que la empresa se ejerza a través de un establecimiento que no tenga carácter territorial (vid. Ley 20/2003, de 7 de julio de protección jurídica del diseño industrial)

9 "Si la empresa tiene su origen en la Economía, y en ella encuentra una Ciencia que la estudia con plenitud, el concepto económico admitido por su doctrina debe ser punto de partida para su estudio desde el Derecho” Luis Hernando Cebriá , La empresa como objeto de negocios jurídicos ( Un estudio a partir de la Jurisprudencia del Tribunal Supremo), Tirant Monografías, Tirant lo Blanch, Valencia 2002, p. 27 
deba ser "algo" vivo y en funcionamiento lo mismo que si se tratara de un ser vivo y que, en cuanto sujeto, deba constituirse como una organización socioeconómica (viva y en funcionamiento también) que puede ser y de hecho es considerada como destinataria de normas jurídicas.

Es en este punto donde se plantea cómo a un ente abstracto, consistente en una

"organización de elementos personales, materiales e inmateriales (...) y [que pretende ] de forma perdurable un objetivo económico determinado" Tribunal de Justicia de las Comunidades europeas; Sentencia de 13 de julio de 1962; asunto 19/61 Mannesman AG/Haute Autorité),

puede serle aplicados, constituyéndose en sujeto de negocios jurídicos, algunos de los criterios interpretativos clásicos en el ámbito de la interpretación de los contratos, en cuanto persiguen descubrir la voluntad de ese ente en el momento de la contratación. ¿Se puede decir que la empresa tiene intención o voluntad a la hora de concluir un contrato? Y si es así ¿Es posible descubrir esa intención o voluntad por los medios a los que tradicionalmente se descubre la voluntad de las personas físicas y/o jurídicas?

El problema anteriormente apuntado se plantea porque el criterio interpretativo fundamental y tradicional del Derecho de obligaciones y contratos, es el de la literalidad de los términos empleados siempre y cuando no dejen lugar a dudas sobre la intención de los contratantes (Artículo 1281 CC). ${ }^{10}$ Por tanto, la primera premisa de la que debemos partir será la de que la intención del contrato que haya sido celebrado por una o varias empresas, será la que reflejen los propios términos del contrato, salvo que ello nos ofrezca algún tipo de dudas sobre el verdadero objeto del mismo, por ejemplo, porque haya contradicciones entre cláusulas contractuales, o entre el contrato y las conductas realizadas por las partes. En tal caso, será necesario acudir a otros criterios interpretativos que, serán, en principio, los que con carácter subsidiario establece el Código Civil español. Así, como primera medida, habrá de atenderse a lo que establece el Artículo 1282 del mismo texto legal en cuya virtud.

"Para juzgar de la intención de los contratantes, deberá atenderse principalmente a los actos de éstos, coetáneos y posteriores al contrato"

Sin embargo, la aplicación de tal criterio no resulta tan sencilla como a primera vista pudiera parecer puesto que, en el caso de la empresa, los actos realizados

10 Es en este punto donde se empiezan a plantear problemas en la interpretación del contrato, como se ha señalado anteriormente, cuando aquel ha sido precedido de una carta de intenciones y se produce una discrepancia terminológica entre ambos. Evidentemente, debe prevalecer el sentido de los términos utilizados en el contrato. Ello resulta fácil cuando dichos términos son claros; el problema surge cuando no lo son: es aquí cuando deberán entrar en juego otros criterios de interpretación del contrato, apareciendo la carta de intenciones como medio de reforzar y asegurar el sentido de dicha interpretación. 
por ésta pueden obedecer a políticas económicas o corporativas que pueden variar en el tiempo, según la coyuntura económica, productiva, laboral o incluso social de la época de que se trate, o de la composición de la Junta de accionistas y de la personalidad de los socios. Sin embargo, el cambio de política empresarial en un momento determinado no puede afectar (no debería afectar), por ejemplo, a un contrato concluido, en un momento inmediatamente anterior en el tiempo al cambio de algunos o de la mayoría de los miembros del Consejo de Dirección de una empresa del tipo que sea.

Un problema similar se puede plantear en cuanto al tercer criterio interpretativo que establece el Código Civil (Artículo 1283), es decir, atender al propósito que guiaba a las partes en el momento de celebrar el contrato. Cuando el contrato es celebrado por una empresa cabe que el propósito permanezca o deba permanecer en secreto para evitar la frustración de posibles objetivos comerciales. En este caso, por tanto, habrá de acudirse a algún otro criterio que permita la completa integración del contrato celebrado por aquélla: es aquí donde la carta de intenciones adquiere todo su sentido como elemento para la interpretación del contrato ${ }^{11}$. Como dice la Sentencia del 11 de julio de 1994, en el caso de que un sujeto,

"aún sin exteriorizar de modo directo su querer mediante palabra escrita u oral, adopta una determinada conducta basada en los usos sociales y del tráfico, tal conducta ha de ser valorada como expresión de la voluntad interna".

Por tanto, dicha conducta (en este caso la suscripción de la carta de intenciones), debe ser tenida en cuenta en cuanto que medio de averiguar la voluntad de la parte al contratar. ${ }^{12}$

\section{LA CARTA DE INTENCIONES COMO ELEMENTO INTERPRETATIVO DE LOS CONTRATOS DE EMPRESA}

Los problemas apuntados en los apartados anteriores, así como la necesidad de hacer frente a la rapidez e inmediatez que es una de las características propias del tráfico jurídico mercantil, y una de cuyas exigencias es la de no tener que interrumpir la ejecución de un contrato cada vez que puedan surgir dudas sobre su interpretación, han hecho que se hayan articulado distintas soluciones para intentar prever desde un principio todos los posibles problemas que se pueden plantear en la ejecución de un

11 Según la Sentencia de 8 de marzo de 1995, en la interpretación del contrato se ha de tener en cuenta la voluntad bilateral de ambas partes, quedando excluida como regla general la mera voluntad interna de cualquiera de ellas o de las dos.

12 En contra Francisca Llodrá Grimalt, que, en su artículo "Letter of intent, carta de intenciones, precontrato" en la Revista Derecho de los Negocios, Abril 2003, recuerda que "el hecho de que un acuerdo sea incompleto es una clara muestra de que no se ha producido una auténtica voluntad de obligarse, en los términos hasta el momento negociados" 
contrato mercantil y arbitrar las posibles soluciones. Este estudio se centra en la más importante de esas soluciones recibe el nombre de "carta de intenciones" así como el de la función que le corresponde en la interpretación e integración del contrato es el objeto del presente trabajo.

Las exigencias de la buena fe, que exige una actuación, tanto en la fase de preparación del contrato como en la fase de conclusión y ejecución del mismo, ajustada al deber de comportamiento honrado y justo, determinan que todas las personas, todos los miembros de una comunidad jurídica deban comportarse conforme a ella en su relaciones recíprocas. Se trata de la buena fe en sentido objetivo a que se refieren los artículos 7.1 y 1258 del CC español. La buena fe

"in contrahendo" "significa un comportamiento leal en las relaciones sociales, causa justificativa de la confianza y, al mismo tiempo, exigencia imprescindible en la conducta preparatoria del negocio. Las partes tienen la obligación de comportarse según la buena fe en el sentido de que a ellas incumbe la carga de una lealtad recíproca de conducta socialmente valorable y exigible"13.

Uno de los principios básicos del Derecho español de obligaciones y contratos es el principio apuntado, que también debe observarse (y especialmente) en la fase preliminar. Dicha idea aparece también recogida en todas las propuestas internacionales de regulación del derecho contractual ${ }^{14}$. Pues bien, ante la duda sobre la interpretación del contrato celebrado por la empresa y ante el fracaso en la utilización del resto de los criterios interpretativos habrá de acudirse, subsidiariamente, al principio de la buena fe contractual (Artículo 1258 del Código Civil), que

"corregirá y orientará integrativamente la voluntad privada que da vida al negocio jurídico, o a estos tratos que tienden a producir cierta eficacia en el ámbito de la negociación, aunque no participen de la naturaleza contractual". ${ }^{15}$

Sin embargo, la aplicación del principio de la buena fe contractual, conlleva una serie de dificultades como, por ejemplo, determinar cuáles pueden ser las consecuencias que, según la buena fe, derivan de ese contrato y cuáles las que no se deberían entender incluidas en ese concepto de la buena fe. ${ }^{16}$

13 Alonso Pérez, M. La responsabilidad precontractual Revista Jurídica de Cataluña, 1971, p. 889

14 Principios Unidroit Arts. 2.14 y 71, PECL 1:201, 1:202, 1:1106, 2:301

15 J.L de los Mozos, El principio de la buena fe, sus aplicaciones prácticas en el Derecho civil español, Barcelona 1965, pp.124 y ss. También La conversión del negocio jurídico, Barcelona, 1959, pp. 52 y ss.

16 En la Sentencia del Tribunal Supremo de 8 de Julio de 1981, el alto Tribunal, interpretando el artículo 7.1 del CC señala que, en dicho precepto, la buena fe supone una exigencia "de una conducta ética significada por los valores de la honradez, lealtad, justo reparto de la propia responsabilidad y avenimiento a las consecuencias que todo acto consciente y libre pueda provocar en el ámbito de la confianza ajena" 
La carta de intenciones, al plasmar por escrito la intención inicial de las partes al contratar $^{17}$, ofrece elementos decisivos para determinar en qué sentido debe entenderse celebrado el contrato y, por tanto, qué es lo que la buena fe hace que deba entenderse incluido en el mismo. Efectivamente, la carta, en principio, tiene que identificar cuál es el objeto de la negociación. Al menos, como se verá posteriormente, deberá también ilustrar a la otra parte sobre aquellos extremos en que sería preciso llegar a algún tipo de acuerdo, y normalmente, incluirá expresiones del oferente por las que se determina que el contrato deberá contener las cláusulas habituales de este tipo de contrato y establecer remedios adecuados. Se trata de una función de anticipación que puede adoptar distintas formas expresivas y documentales.

Dichas expresiones sirven, obviamente, desde un punto de vista positivo pero también desde un punto negativo, al permitir presuponer que si el objeto del contrato debe ser uno concreto, el hecho de que se llegue a acuerdos parciales no definitivos impedirá que se entienda concluido ningún tipo de acuerdo. En otras palabras la identificación del objeto de la negociación y la determinación de algunos extremos mínimos para entender concluido en algo el acuerdo, impiden que, si el acuerdo completo no se produce, la otra parte pueda hacer valer, como acuerdos parciales, los términos ya convenidos, todo ello en aplicación del principio de la buena fe contractual.

Por otro lado, con el fin de facilitar la labor de interpretación del contrato a celebrar, puede insertarse en la carta de intenciones como Anexo, aunque ello no es muy frecuente, un texto ilustrativo de lo que debería ser el contrato futuro. Naturalmente, este texto es meramente orientativo y no vincula a las partes en la negociación. Pero el oferente debe dejar claro que ese Anexo, tampoco constituye para él, oferta vinculante susceptible de ser aceptada por la otra parte o, lo que es más probable, susceptible de poder ser utilizada unilateralmente por la otra parte para imponer a los términos del acuerdo futuro, o para colmar lagunas de la interpretación. La prudencia aconseja ser extremadamente cuidadoso con el uso de esta práctica, que tiene muchas veces un significado jurídicamente equívoco que los negociadores no suelen tener en cuenta, pero que comporta riesgos no queridos, especialmente cuando el Anexo está, a su vez, firmado o suscrito de alguna forma por las partes. Para evitar que este Anexo, al haber sido firmado por las partes, sea considerado como compromiso vinculante, debe expresarse de manera muy explícita que dicho Anexo se firma exclusivamente como manifestación de hechos de que esto es lo que se negociaba y a partir de lo cual se debe seguir negociando.

En resumen, son diversos los criterios que pueden utilizarse en la interpretación de los contratos celebrados por la empresa. En defecto de otros (por ejemplo literalidad de los términos, conductas simultáneas anteriores o posteriores u otro) deberá utilizarse el criterio de la buena fe contractual, pero, ante la vaguedad e imprecisión de éste, la carta de intenciones actuará a modo de "soporte interpretativo", al fijar a priori el objeto, los términos y el alcance del contrato.

17 Con expresiones tales como A propone a B; le comunico mi intención de ... 


\section{LA CARTA DE INTENCIONES: CONCEPTO Y DISTINCIÓN DE FIGURAS AFINES}

\section{III.I. Concepto y contenido de la Carta de Intenciones}

Llegado este punto, parece inexcusable dar una definición de qué se entiende por ese documento, carta de intenciones, que tantas cuestiones plantea (si puede entenderse como acuerdo contractual, si puede o debe ser utilizado como elemento interpretativo del contrato y todos los que ya se han apuntado a lo largo de este trabajo). Como se ha señalado al inicio de este trabajo, en el ámbito del Common Law el término letter of intent hace referencia a toda clase de documentos precontractuales, dentro de los cuales se englobarían: los documentos que plasman una invitación a negociar (que serían lo que en este trabajo se denominan como carta de intenciones propiamente dicha), que indican que el asunto está en fase de negociación por lo cual el documento en sí es incompleto e inejecutable; los documentos que reflejan los tratos preliminares llevados a cabo por las partes, es decir, unos documentos bilaterales que contienen el estado de las negociaciones (que llamaremos pactos deintenciones) cuyo objeto es fijar lo que se ha conseguido hasta el momento $\mathrm{y}$, finalmente, los acuerdos preliminares vinculantes, es decir, precontratos. En los precontratos la contratación posterior es una mera formalidad, mientras que en los pactos o cartas de intenciones, es más que una simple formalidad.

A la hora de concretar más precisamente qué se entiende por carta de intenciones, lo primero que hay que tener en cuenta es que éste es, casi siempre un documento escrito $^{18}$. No tiene un amplio juego aquí la aplicación del principio de libertad de forma propio del Derecho de contratos, y no porque nos encontremos ante uno de los supuestos en que la ley exija forma escrita para hacer efectivas las obligaciones derivadas de un contrato (entre otras cosas porque la carta de intenciones no es un contrato salvo excepciones ${ }^{19}$, como veremos posteriormente, ni de ella surgen obligaciones de ningún tipo también salvo excepcione ${ }^{20}$ ), sino, fundamentalmente, porque con éste documento las partes tratan de fijar el punto de partida para una negociación, negociación que normalmente consistirá en integrar una nueva empresa $^{21}$ en aquella empresa que inicia dicha negociación. Es evidente que, si se

18 Este documento "sólo vale como prueba de que existieron [tratos preliminares] y puede servir de orientación para la interpretación del contrato. En ningún caso revelan un contenido negocial" Alonso Pérez, M. “La responsabilidad precontractual”, Revista Jurídica de Cataluña, 1971, pp. 857922

19 Aunque determinadas declaraciones realizadas por las partes pueden constituir un acuerdo perfecto, como es el propio acuerdo de que ninguna de las conductas negociadoras serán valoradas por ninguna de las partes como vínculos contractuales hasta que se produzca el contrato final escrito

20 La anteriormente señalada.

21 Este trabajo se refiere fundamentalmente a contratos de una cierta entidad para la empresa (adquisición de empresas, fusiones, escisiones, etc.), puesto que son este tipo de contratos los que tienen una entidad suficiente como para justificar la elaboración de una carta de intenciones. 
trata de establecer las bases de una negociación, resulta imprescindible que exista una clara y meridiana identificación de los puntos claves de la misma y de su desarrollo ulterior, cosa que sólo puede lograrse a través de la fijación escrita de los términos en los que debe llevarse a cabo el proceso.

Por otro lado, la carta de intenciones (pese a lo que su nombre parece indicar), no es en realidad una verdadera carta, y además no siempre adopta una forma epistolar. Por otro lado, la carta de intenciones ni siquiera tiene siempre carácter unilateral, puesto que en algunas ocasiones es necesaria la aceptación de la carta por parte del destinatario (a través de su suscripción, por ejemplo), para que surta los efectos que le son propios. Por otro lado, en algunas ocasiones no nos encontramos ante una mera intención o propósito sino ante verdaderos compromisos que sientan las bases para negociaciones ulteriores.

A partir de las anteriores premisas, se puede afirmar que la carta de intenciones es el documento unilateral o bilateral en que una o ambas partes de una negociación llevan a cabo una serie de declaraciones. Se trata de simples invitaciones a negociar ${ }^{22}$, documentos unilaterales dirigidos a que otros formulen ofertas o a iniciar negociaciones. En la letter of intent si el receptor quiere seguir negociando lo debe indicar expresamente, sin que exista base alguna para poder interpretar que existe dicha voluntad negociadora, ni siquiera en caso de suscripción de la carta de intenciones ${ }^{23}$.

La carta de intenciones en cuanto documento es, de conformidad con lo anteriormente expuesto, un documento que servirá de base a un proceso negociador ulterior, cuyo contenido está constituido por una serie de declaraciones que pueden ser clasificadas en tres grandes grupos: declaraciones que siempre deben contenerse en una carta de intenciones, declaraciones que sólo se contendrán en una carta de intenciones en caso necesario (por ser las negociaciones que se llevan a cabo muy prolongadas y/o complejas) y declaraciones accesorias. La tabla que se incluye a continuación trata de reflejar esquemáticamente este posible contenido "esencial, natural y accidental" (empleando terminología propia del Derecho de Contratos) de las cartas de intenciones:

22 Lake, R.B. y Draetta, U.: Letters of intent and other precontractual documents. Comparative analysis and forms. Dutterworth Legal Publishers, pg. 88

23 Para que dicha suscripción pudiera ser interpretado, no ya como voluntad de seguir negociando, sino incluso como consentimiento para obligarse, sería necesario que resultaran claros y perfectamente identificados todos los términos del futuro posible contrato, de modo que, mediante la suscripción del documento la parte no pudiera expresar otra voluntad que una de aquéllas. En este sentido el Tribunal Supremo ha venido señalando que (STS 23 de marzo de 1990) "no puede considerarse consentimiento la consignación de una firma después de un texto sin explicación de sus términos, conceptos y extensión de una obligación convenida que ordinariamente se requiere para poder apreciar debidamente su alcance el que la contrae". 


\section{CON CARÁCTER NECESARIO LAS PARTES SIEMPRE}

a. declaran su compromiso/ propósito/ pretensión/ ofrecimiento de comenzar o continuar una negociación que acabe con un acuerdo definitivo de (por lo general) compra o absorción de una empresa

b. establecen los puntos mínimos sobre los cuales habrá de llegarse a un acuerdo y, en el supuesto de compraventa (en este caso, evidentemente, los puntos mínimos serán la fijación de la cosa ${ }^{24} \mathrm{y}$ del precio) y sólo en determinados casos, adelantan una cifra aproximada del precioque se debe pagar

c. en los casos de negociaciones prolongadas y complejas las partes establecen reglas obligatorias de carácter temporal con objeto de regular la negociación futura

\section{CON CARÁCTER ACCESORIO LAS PARTES}

\section{III.II. Figuras afines a la Carta de Intenciones}

\section{III.II.I. El contrato y la carta de intenciones}

\section{El Código Civil establece en su artículo 1254 que}

"el contrato existe desde que una o varias personas consiente en obligarse respecto de otra u otras, a dar alguna cosa o prestar algún servicio".

A la vista de este presupuesto legal y de lo anteriormente expuesto, resulta evidente cuál es la primera diferencia entre el contrato y la carta de intenciones, al menos en el Derecho español: el contrato genera siempre obligaciones entre las partes, sean unilaterales o bilaterales; por el contrario, en las cartas de intenciones las partes declaran que las manifestaciones y propósitos formulados no son vinculantes para ninguna de ellas, a no ser que expresamente se diga lo contrario respecto de alguna/o de ellas/os. Es más, uno de los propósitos que puede perseguir la carta de intenciones es evitar que con las negociaciones llevadas a cabo las partes, queden éstas obligadas más allá de lo que realmente quieren por aplicación del Artículo 1258 del Código Civil, al que, como se ha señalado anteriormente, debería acudirse como criterio interpretativo subsidiario en ausencia de otros o por imposibilidad de aplicación de los mismos.

24 Que en el caso habitual de uso de la carta de intenciones, es decir, en los supuestos de compra o fusión de empresas, adquiere dificultades añadidas, puesto que supone partir de qué se entiende por empresa y cuál es, a su vez, su contenido esencial, natural y accidental. Un apoyo puede encontrarse en la Ley de Hipoteca Mobiliaria y Prenda sin desplazamiento que, a la hora de regular la hipoteca mobiliaria del establecimiento - que es lo que más se aproxima a las "supuestas" garantías constituidas sobre la empresa- señala una serie de elementos esenciales naturales y accidentales que deben tomarse en consideración a la hora de interpretar las cartas de intenciones previas, por ejemplo, a la compraventa de empresas.

25 Bien por el carácter equívoco de dichos pactos, o bien porque los mismos presuponen un estado muy avanzado de la negociación. En este último caso lo que se pretende es establecer la vinculación de las partes con dichos acuerdo, para seguir avanzando desde ellos. 
Enlazado con lo anteriormente expuesto, no se puede olvidar que uno de los principios básicos del Derecho de contratos es el principio de buena fe contractual. A este pueden unirse, en la materia que nos ocupa el principio de "pacta sunt servanda” y, por supuesto, el de autonomía de la voluntad. Según el principio de buena fe contractual que, por otro lado, sirve a la integración de los contratos, estos se perfeccionan por el simple consentimiento y, desde entonces, obligan no sólo al cumplimiento de lo expresamente pactado sino también a todas las consecuencias que según su naturaleza sean conformes a la buena fe (...). Si aplicamos estrictamente este principio al ámbito que rodea a la empresa y, especialmente, al ámbito de las negociaciones que suelen envolver cualquier negocio jurídico que pueda celebrar ésta, nos daremos cuenta que el nacimiento de la figura de la carta de intenciones ha sido una verdadera necesidad provocada, entre otros aspectos, por la complejidad de las negociaciones que se llevan a cabo por una empresa con carácter previo a la conclusión de cualquier tipo de contrato, complejidad que alcanza su grado sumo cuando ese contrato va a tener por objeto la adquisición o la absorción de la fusión con otra empresa. Así, cualquiera de los actos realizados en dichas negociaciones previas podría, en base al criterio interpretativo señalado, ser considerado como un consentimiento presunto para la contratación, lo cual podría dar lugar a generar una obligación allí donde no ha habido voluntad de obligarse ni de contratar e, incluso, sobre la base de una interpretación amplia de cuáles son las obligaciones a que puede dar lugar la buena fe, con un consentimiento específico para obligarse respecto de determinados extremos que pueden encontrarse muy lejos de lo que la empresa negociadora pretendía en un primer momento.

Como hemos dicho, es ésta una de las razones que motivó la aparición, primeramente en el Derecho Anglosajón, mucho más ágil y sensible a las necesidades planteadas por la práctica en el tráfico jurídico económico, y después en el Derecho continental, de la carta de intenciones en el ámbito de las debidas diligencias. Pero, así como la carta de intenciones aparece en primer lugar como salvaguardia frente a cualquier interpretación de la existencia de una voluntad de contratación, también se nos presenta como un soporte de carácter documental que contiene premisas básicas y fundamentales para la interpretación del contrato una vez celebrado. En este sentido, se podría establecer un paralelismo entre la interpretación de la Ley y la interpretación del contrato (que es Ley entre las partes contratantes), de manera que la carta de intenciones se configuraría como una especie de "antecedente", posibilitando igualmente el elemento espiritual en la interpretación de la "ley" contractual.

Por otro lado, desde el punto de vista del contenido de una y otra figura jurídica, mientras que el contrato contiene una serie de manifestaciones que poseen carácter vinculante y fuerza obligatoria "ab initio", la nota fundamental que define las cartas de intenciones radica en que éstas incluyen manifestaciones que carecen de todo efecto jurídico -sin necesidad de establecer expresamente de una regla sobre no vinculación- bien porque exista una contradeclaración o reserva, bien porque el objeto sea absolutamente indeterminado. 


\begin{tabular}{|c|c|}
\hline \multicolumn{2}{|c|}{ Diferencias fundamentales entre el contrato y la carta de intenciones } \\
\hline Contrato & Carta de Intenciones \\
\hline $\begin{array}{c}\text { Obligatoriedad y vinculación para las } \\
\text { partes que lo celebran }\end{array}$ & $\begin{array}{c}\text { No obligatoriedad salvo en las cláusulas respecto de las que } \\
\text { se pacte expresamente }\end{array}$ \\
\hline $\begin{array}{c}\text { Es necesario acudir a elementos } \\
\text { externos para proceder a su } \\
\text { interpretación }\end{array}$ & $\begin{array}{c}\text { Ofrece criterios y pautas interpretativas del contrato al que } \\
\text { antecede }\end{array}$ \\
\hline $\begin{array}{c}\text { Representa el resultado de la } \\
\text { negociación }\end{array}$ & $\begin{array}{c}\text { Prepara la negociación para la consecución de un contrato } \\
\text { futuro }\end{array}$ \\
\hline
\end{tabular}

\section{III.II.II. El Precontrato y la Carta de Intenciones}

Ya se ha señalado en otros apartados de este trabajo que tanto precontrato como carta de intenciones son dos especies de un mismo género: los tratos preliminares en la contratación. Las diferencias entre uno y otro son paralelas o semejantes a las anteriormente expuestas. Efectivamente, la frontera entre el precontrato y la carta de intenciones se encuentra, fundamentalmente, como en el caso anterior, en la obligación de contratar qué implica el primero y qué no conlleva la segunda.

Para la doctrina clásica, el contrato preliminar es un "contrato perfecto y obligatorio que tiene por fin asegurar la celebración de un determinado contrato futuro" ${ }^{26}$. Roca Sastre define el precontrato como un contrato base en el cual las partes prometen la realización de la actividad consistente en el conjunto de actividades necesarias para su conclusión definitiva, con lo que el precontrato sería, según Roca, un contrato en virtud del cual las partes sientan las líneas básicas de un contrato específico y contraen la obligación de desenvolverlas o desarrollarlas en lo futuro, a fin de que aquel último quede en definitiva completo y concluso"27. De Castro sin embargo, considera que el precontrato constituye una de las etapas propias del iter negocial, que estaría constituido por una fase preliminar consistente en la promesa de celebrar un contrato (precontrato) y la exigencia de su cumplimiento.

La Jurisprudencia del Tribunal Supremo ha venido a fijar el concepto de precontrato de acuerdo a otros criterios. Así, la STS 391/2001 (Sala de lo Civil) del 20 de abril, señala que el precontrato es un contrato preliminar o preparatorio que, en cuanto orientado (por ejemplo) a una compraventa, tiene un régimen distinto del de la compraventa misma. Por otro lado, sentencias como la del 25 de junio de 1993 (RJ 1993\5384) (recurso núm. 3503/1990), señalan que la distinción doctrinal y jurisprudencial entre la promesa bilateral de compra y venta y el contrato definitivo de compraventa se centra "en la existencia o no de una voluntad negocial, dirigida a definir para un momento posterior la entrada en vigor del contrato proyectado, quedan, mientras tanto, solamente ligadas las partes por el peculiar vínculo que produce el precontrato, y que consiste en "quedar obligado a obligarse". 
Las anteriores definiciones nos dan el dato fundamental para distinguir entre precontrato y carta de intenciones. Así, el precontrato se configura ya en sí mismo como un auténtico contrato que tiene por objeto celebrar otro en un futuro ${ }^{28}, \mathrm{y}$ contiene el proyecto o la ley de bases del siguiente. Como ya se ha señalado, en el precontrato, la celebración del contrato que prepara es una mera formalidad ${ }^{29}$. Las cartas de intenciones, sin embargo, y como ya se ha señalado en el apartado anterior, incluyen manifestaciones que carecen de todo efecto jurídico -sin necesidad de establecer expresamente de una regla sobre no vinculación-, bien porque exista una contradeclaración o reserva, bien porque el objeto sea absolutamente indeterminado.

Sin embargo, existe una característica que acerca la carta de intenciones al precontrato: el carácter preparatorio que tienen una y otro. Ambos pretenden hacer frente a una situación en la que, como no esposible contratar todavía, las partes o, al menos uno de ellos, tratan de crear un "status" jurídico que haga viable la contratación en un futuro. La diferencia se ha señalado anteriormente y se reitera aquí: en el precontrato se crea la obligación de contratar en un futuro ${ }^{30}$; en la carta de intenciones, simplemente se favorece que dicho contrato pueda ser concluido. Por todo ello, resulta evidente que, esta etapa de tratos preliminares que materializa la carta de intenciones, implica

28 No faltan posturas negadoras de esta afirmación. Así Antonio Román García en "El precontrato: estudio dogmático y jurisprudencial” Ed. Montecorvo S.A.1982, p. 175, señala que "al negarnos a considerar el precontrato como un negocio generador de una obligación encaminada a la posterior celebración de otro contrato, (...) la utilización de esta especial figura jurídica responde a la imposibilidad o dificultad material o jurídica de las partes para concluir en este momento el contrato principal proyectado"

29 "El cumplimiento de la obligación contraída en el precontrato tiene por resultado preciso- junto con la operación indispensable por parte del acreedor- la conclusión de otro contrato, el llamado contrato principal. (...). (En el precontrato, surge) una obligación de emitir una declaración de voluntad, de realizar un acto externo" Alguer, J. "Para la crítica del concepto de precontrato" Revista de Derecho Privado, 1935, T.XXII, pp. 370 y ss.

30 En este punto puede ser interesante recordar aquí el tenor literal del Artículo 708 de la Ley de Enjuiciamiento Civil del año 2000. Según dicho precepto cuando en una Sentencia se haya condenado a la emisión de una declaración de voluntad, la falta de ejecución voluntaria permitirá que el Juez la supla si estuvieren determinados los elementos esenciales del negocio. Si alguno de esos elementos esenciales no estuviera determinado, el Juez lo determinará de acuerdo a lo que sea usual en el mercado o en el tráfico jurídico, y si la indeterminación afectare a los elementos esenciales del contrato procederá la indemnización de daños y perjuicios.

De aquí se puede deducir una última diferencia entre precontrato y carta de intenciones basada en la distinta responsabilidad que surge para la partes en uno y otro caso; en caso de incumplimiento de la obligación de contratar en el futuro que genera el precontrato, el Juez sustituirá su declaración si están determinados todos los elementos esenciales; si alguno de ellos falta pero puede determinarse de acuerdo a la costumbre en el tráfico, lo determinará y emitirá la declaración de voluntad. En cambio, si los elementos esenciales están indeterminados, cosa que ocurre normalmente en las cartas de intenciones, el Juez sólo puede condenar, en su caso, a las partes por los daños y perjuicios ocasionados a la otra parte siempre que (STS 14 de junio de 1994): I) haya existido una razonable situación de confianza respecto de la celebración del contrato II) la ruptura de tratos resulte injustificada III) se haya producido un resultado dañoso IV) exista una clara relación de causalidad. 
"un debate de las partes en torno al contenido del posible contrato posterior, para lo cual se intentan aproximar los puntos de vista, con una voluntad de intercambiar opiniones y discutir acerca del eventual contenido del negocio futuro, no necesariamente, por tanto, con una voluntad de contratar" ${ }^{31}$

Desde otro punto de vista y en lo que se refiere al desarrollo del iter negocial, la situación de la carta de intenciones en cuanto preparatoria del futuro contrato, nos conducirá necesariamente a efectuar en esta fase preliminar de la contratación una serie de delimitaciones, distinguiéndose los tratos preliminares materializados en la carta de intenciones,

"de la formulación de la oferta de contrato y del precontrato como una fase autónoma del esquema negocial que culminará con la conclusión del contrato principal" 32 .

\begin{tabular}{|c|c|}
\hline \multicolumn{2}{|c|}{ Diferencias fundamentales entre el precontrato y la carta de intenciones } \\
\hline Precontrato & Carta de Intenciones \\
\hline $\begin{array}{c}\text { Las partes deberán celebrar en el futuro el } \\
\text { contrato que ahora se prepara }\end{array}$ & $\begin{array}{l}\text { No obligatoriedad salvo en las cláusulas } \\
\text { respecto de las que se pacte expresamente }\end{array}$ \\
\hline $\begin{array}{l}\text { El precontrato contiene todos los elementos } \\
\text { esenciales del contrato definitivo }\end{array}$ & $\begin{array}{l}\text { Ofrece criterios y pautas interpretativas del } \\
\text { contrato al que antecede }\end{array}$ \\
\hline $\begin{array}{l}\text { La obligación fundamental consiste en celebrar } \\
\text { un contrato de una especie determinada y } \\
\text { expresada en el propio precontrato }\end{array}$ & $\begin{array}{l}\text { Prepara la negociación para la celebración de } \\
\text { un contrato futuro que, incluso, puede ser a su } \\
\text { vez un precontrato }\end{array}$ \\
\hline $\begin{array}{l}\text { Constituye la materialización de los tratos } \\
\text { preliminares del contrato }\end{array}$ & Constituye la fase previa a la firma del contrato \\
\hline
\end{tabular}

\section{III.II.III. Las Cartas de Intenciones y las Meras Declaraciones de Voluntad}

Como señala Albaladejo ${ }^{33}$ la declaración de voluntad es la conducta por la cual el sujeto exterioriza voluntaria y conscientemente lo querido. De dicha declaración debe poder inferirse una determinada voluntad negocial, de manera que si la declaración resulta ininteligible o tiene varios sentidos posibles, sin que pueda decidirse racionalmente por uno de ellos no hay verdadera declaración de voluntad, la declaración de voluntad supone dos voluntades; la voluntad declarada cuyo

31 Antonio Román García, "El precontrato, estudio dogmático y jurisprudencial” Ed. Montecorvo. S.A. Madrid 1982, p. 369

32 Antonio Román García “ El precontrato, Estudio dogmático y jurisprudencial, Ed Montecorvo SA Madrid 1983

33 Derecho Civil, TOMO I, Introducción y parte general, VOLUMEN II, La relación, las cosas y los hechos jurídicos, pp. 170 y ss. 
objeto o contenido es el negocio, y la voluntad de declarar cuyo objeto es la propia declaración. La primera es la que deberá descubrirse mediante la interpretación de la declaración realizada. En cualquier caso, cualquier declaración de voluntad implica, en mayor o menor medida, la disposición de la parte que emite dicha declaración para conseguir aquello que es objeto de la misma. En cambio en la carta de intenciones las partes no pretenden sino fijar unas bases que permitan decidir (por la determinación de un objeto concreto) si se emitirán o no las declaraciones de voluntad (oferta y aceptación) que desembocarán en la celebración de un contrato en el futuro ${ }^{34}$.

\section{III.II.IV. Las cartas de intenciones y las ofertas para negociar}

La principal y decisiva diferencia entre la carta de intenciones y la oferta contractual, radica en lo que señala la Sentencia de 10 de octubre de 1980 según la cual

"la fase de tratos preliminares es distinta de la oferta en cuanto declaración de voluntad de naturaleza recepticia, como tal dirigida al otros sujeto y emitida con un definitivo propósito de obligarse si la aceptación se produce, surgiendo en consecuencia el consentimiento por la coincidencia de esas declaraciones de los contratantes en que la oferta y la aceptación consisten, de donde se sigue que encaminados los tratos preliminares a la formación de la primera, desaparecerán una vez cumplida su misión en el momento que en el iter contractual se llegó a formular una proposición final, con todas las notas de una verdadera oferta (...), realizada la oferta de contrato o propuesta conteniendo los requisitos indispensables al fin proyectado y por consiguiente con todos los elementos necesarios para el futuro contrato (...) el contrato se genera en su perfección con el asentimiento de la otra parte manifestando su aceptación a los términos en que aquella declaración ha sido hecha por el oferente y alcanzándose, en suma, el in idem placitum o punto de conjunción de los intereses contrapuesto que es el acuerdo determinante del consentimiento cuya suficiencia para la perfección del negocio viene proclamada por el Art. 1254 del CC."

Resulta obvio que, en la interpretación jurisprudencial, la carta de intenciones no es más que una fase de los tratos preliminares que actúan como paso previo para la oferta, culmen de todo el iter negociador, oferta que debe contener en sí todos los elementos que serán necesarios para el futuro contrato, y que, en concurrencia con la aceptación de la otra parte, dará lugar al contrato.

34 La Sentencia de 28 de enero de 200, de 31 de diciembre de 1998 de 16 de diciembre de 1998 entre otras se ponen de acuerdo en que la fase de tratos previos es distinta de cualquier tipo de declaración recepticia entre las que se encuentra la oferta 


\section{FORMACIÓN DE LA CARTA DE INTENCIONES}

\section{IV.I. Identificación del objeto de la negociación}

La formación de la carta de intenciones comienza por un paso que, no por obvio, resulta menos importante en cuanto al futuro contrato a celebrar por la empresa. Dicho paso no es otro que la identificación del campo concreto al que se referirá el contrato que en su día suscribirán las partes y tiene mucho que ver con las actividades de análisis estratégico del mercado que constituyen uno de los ámbitos en que las modernas empresas deben desplegar su mejor hacer.

Para poder mantener una posición ventajosa en un mercado cada vez más competitivo, las empresas tienen que ser muy conscientes de sus debilidades y de sus fortalezas, de cuáles son las amenazas que sufren y las oportunidades que deben aprovechar. Al mismo tiempo, es necesario que los objetivos empresariales se fijen de acuerdo a la finalidad que las empresas persiguen en el mercado, así como que éstas definan los medios más adecuados para lograr dichos objetivos. Todas estas actividades pueden resumirse muy brevemente: es necesario que la empresa sepa qué es lo que quiere, por qué lo quiere y cómo conseguirlo. Sólo así podrán los contratantes asegurarse el éxito en una negociación que comienza con una manifestación al destinatario de la carta de intenciones relativa al propósito o los deseos de iniciar y llevar a buen fin una negociación cuyos términos resultan difíciles de identificar concretamente a priori.

La identificación del campo concreto en que se va a contratar y la decisión relativa al tipo de contrato a celebrar, son criterios que van a actuar también como pautas interpretativas del futuro contrato y ello como consecuencia natural de la propia actividad empresarial y por aplicación del Artículo $1258 \mathrm{CC}$. Efectivamente, en principio el contrato se extenderá a todo aquello que resulte habitual en ese concreto campo empresarial y a todos los efectos que el tipo de contrato que se celebre suele llevar aparejado en ese campo empresarial.

\section{IV.II. Elementos esenciales de la carta de intenciones}

Identificado el objeto de la negociación, lo habitual es que la parte que elabora la carta de intenciones y, por tanto, manifiesta su voluntad de celebrar un contrato, fije a su vez aquellos extremos sobre los que, al menos, deben versar las negociaciones. Estos son los elementos que podríamos considerar necesarios, los cuales proporcionan pautas valiosísimas para la posterior interpretación del contrato que surgirá si las negociaciones concluyen satisfactoriamente, como consecuencia de la ejecución de la mencionada carta de intenciones. En cuanto a la primera de ellas permite afirmar que lo que se quiso por el oferente fue un tipo de contrato y no otro y, por tanto, que se quisieron los elementos esenciales que ese tipo de contrato implica. 
Identificado el objeto de la negociación, lo habitual es que la parte que elabora la carta de intenciones y, por tanto, manifiesta su voluntad de celebrar un contrato, fije a su vez aquellos extremos sobre los que, al menos, deben versar las negociaciones. Estos son los elementos que podríamos considerar necesarios, los cuales proporcionan pautas valiosísimas para la posterior interpretación del contrato que surgirá si las negociaciones concluyen satisfactoriamente, como consecuencia de la ejecución de la mencionada carta de intenciones. En cuanto a la primera de ellas permite afirmar que lo que se quiso por el oferente fue un tipo de contrato y no otro y, por tanto, que se quisieron los elementos esenciales que ese tipo de contrato implica.

Más importancia tiene la declaración del oferente en cuanto a los extremos mínimos sobre los que deben versar las negociaciones, declaración imprescindible en una carta de intenciones y a la que ya se ha hecho referencia en apartados anteriores. Tal declaración cumple dos funciones fundamentales en la interpretación del contrato: una positiva y otra negativa. En lo que se refiere a la primera, la consecución de acuerdos sobre todos los puntos señalados permitirá suponer que existe contrato y que esa es la voluntad del oferente. En cuanto a la segunda, el hecho de que no se llegue a un acuerdo sobre todos los puntos fijados por éste, impedirá que se pueda entender que se ha celebrado un contrato o, lo que es lo mismo, impedirá que se admita la existencia de presuntos acuerdos parciales.

Junto a la fijación del propósito de la negociación y de los elementos mínimos de la misma, es también muy común encontrar en la declaración del oferente expresiones relativas a que el contrato deberá contener las cláusulas habituales de este tipo de contratos y establecer remedios adecuados. En realidad esta declaración no es ni más ni menos que la admisión por parte del oferente de que le sean aplicadas las consecuencias que se deriven de los usos en el ámbito empresarial en que se desenvuelva la negociación. De nuevo nos encontramos ante la aplicación del principio de la buena fe en la contratación mercantil.

Identificados los objetivos perseguidos y los medios con que se cuenta para la consecución de aquéllos, resulta necesario investigar las características condiciones y medios de aquello que va a constituir el objeto del contrato. Una vez definido el campo sobre el que queremos actuar e identificado el objetivo empresarial, se elabora la carta de intenciones que, una vez aceptada por la otra parte, permitirá el inicio del proceso denominado de "due diligence", en aquellos supuestos en que el objeto del contrato sea a su vez una empresa que va a ser el objeto de una compra ${ }^{35}$, que va a

35 En estos casos son fundamentales los llamados pactos de confidencialidad. Efectivamente, en cualquier supuesto de adquisición de empresas, es habitual que el adquirente exija una información exhaustiva sobre aquello que adquiere. En este caso resulta fundamental la obligación de confidencialidad que el adquirente debe asumir. En este sentido, señala Bercovitz "En la negociación de la transmisión de una empresa, se plantean habitualmente determinados aspectos que deben tenerse en cuenta(...) el transmitente debe asegurarse de que la información que sobre la misma se ofrezca al adquirente potencial tendrá carácter confidencial. Para ello será un paso preliminar la firma por ese adquirente potencial de un pacto de confidencialidad, esto es, que mantendrá reservadas las informaciones que se le faciliten, que no podrá facilitar a terceros ni 
integrarse en otra tras un proceso de fusión.

El proceso de "due diligence" puede definirse como aquel proceso cuyo objeto fundamental es la obtención de información sobre los distintos aspectos legales de la sociedad objeto del contrato a celebrar y la comprensión de los distintos factores que deben considerarse en el momento de la compraventa en su caso, o en el momento de la inversión correspondiente ${ }^{36}$. El proceso de due diligence se suele materializar en la elaboración del correspondiente cuestionario de "due diligence" legal que ofrece también, al igual que la carta de intenciones, elementos que facilitarán la interpretación del contrato final al arrojar luz sobre qué era aquello que perseguían los contratantes con el concreto contrato de que se trate. Por ejemplo, el hecho de que el cuestionario de "due diligence" legal incida especialmente sobre la mayor o menor importancia de las deudas pendientes de la empresa a adquirir demuestra, al menos indiciariamente, que el adquirente no está dispuesto a adquirir la empresa a cualquier precio sino sólo en una determinada situación contable que será posteriormente fijada en el contrato. En cambio la ausencia de preguntas en el cuestionario de "due diligence" sobre deudas pendientes, unido a la no inclusión de esta materia en la carta de intenciones, permitirá presumir que cualquier cláusula del futuro contrato en la que el adquirente se haga cargo de las deudas pendientes debe ser interpretada en toda su extensión, haciéndose así de todas las deudas pendientes, cualquiera que sea su cuantía, sin que se pueda aplicar con carácter prevalente el principio de la buena fe contractual. De la misma manera, una exhaustiva referencia en la carta de intenciones a los derechos de propiedad industrial, su valor, situación y demás, permitirá suponer que la adquisición de la empresa en su caso no se producirá sin las mismas.

\section{IV.III. Funciones de la carta de intenciones}

En apartados anteriores se ha hecho ya referencia a algunas de las funciones más habituales de la carta de intenciones, Sin embargo, dichas funciones no agotan las que con carácter ordinario cumplen estas. El presente apartado trata de sistematizar mínimamente dichas funciones así como de explicar mínimamente cada una de ellas.

La carta de intenciones, una vez firmada por ambas partes, representa una especie de "acuerdo preliminar" sin carácter vinculante. Generalmente, como ya se ha señalado anteriormente, describe los principales términos y condiciones de la transacción y deja los definitivos para el compromiso de compraventa, que deberá ser firmado posteriormente. A menudo, incluirá cláusulas de escape que permitan al

aprovechar por sí mismo si no llega a producirse la transmisión”. Cabe preguntarse si ello va a permitir realizar una interpretación del contrato en el sentido de considerar que el incumplimiento de esta obligación por parte del adquirente facultará al transmisionario para rescindir el contrato y para exigir el resarcimiento de los correspondientes daños y perjuicios.

36 Rosana Hallett Charro, "Due Diligence" en "Régimen Jurídico de las adquisiciones de empresas" óp. cita, p. 137 
comprador o al vendedor interrumpir la transacción si cambiasen las circunstancias antes de firmar el compromiso de compra.

Por otro lado, las funciones de la carta de intenciones variarán según quien sea la parte que la elabore y presente. Si la presenta el comprador, hace la misma función que una oferta y espera el comprador que el vendedor realice una contraoferta o una indicación al adquirente de que revise la oferta inicial. Aquí la carta de intenciones es más un medio de comunicación inherente al proceso de negociación que un acuerdo legal.

La carta de intenciones puede ser de tipo genérico o de tipo específico según la voluntad del comprador. El primer tipo sólo se refiere a los puntos más importantes a acordar en la negociación que deja el resto para posteriores negociaciones. El segundo tipo obliga más a las partes comprometiéndolas legalmente respecto de determinados puntos.

De acuerdo a lo anteriormente expuesto, las funciones más importantes de la carta de intenciones, pueden esquematizarse en tres grandes grupos:

1. La carta de intenciones sintetiza y clarifica lo que ya se ha acordado. Si existe algún aspecto que no ha sido comprendido de igual forma por alguna de las partes, contribuye a aclararlo.

2. La carta de intenciones fija un acuerdo de principio, de modo lo suficientemente detallado para que los abogados y expertos fiscales trabajen en el acuerdo final.

3. La carta de intenciones funciona como un refuerzo de la obligación de competencia leal que imponen las leyes, funcionando como una especie de prohibición que impide al oferente negociar otros posibles acuerdos al margen de aquel que prepara la carta de intenciones.

\section{IV.IV. Cláusulas más habituales en la carta de intenciones}

Las cartas de intenciones suelen incluir, como más habituales ${ }^{37}$, una serie de cláusulas, que funcionan como delimitadoras de la invitación a negociar que suponen, centrándonos en un supuesto de compraventa. La carta de intenciones en principio incluiría las siguientes cláusulas:

a. Una oferta de adquisición a un precio estipulado

b. Una explicación de la forma de pago

c. Una descripción de lo que el comprador quiere adquirir (por ejemplo, una división, los activos de la compañía, la propia compañía u otros. )

d. Las principales condiciones unidas a la oferta

e. El acuerdo por parte del vendedor de proporcionar al comprador la debida

37 En los supuestos de adquisiciones y de fusiones de empresas que son en los que estamos centrando fundamentalmente este trabajo 
información de cara a completar la adquisición

f. Un acuerdo por el que ambas partes se comprometen a no negociar con terceros

g. Una descripción de los pasos necesarios para concluir el acuerdo

h. El tiempo límite de la oferta

i. Los objetivos contables y fiscales de ambas partes

j. La forma en que se van a tratar los restantes instrumentos de deuda del vendedor (opciones, warrants, obligaciones convertibles y demás)

k. Si el comprador va a asumir la deuda del vendedor o no

1. ¿Qué ocurrirá si existe cláusula de protección sobre la deuda del vendedor?

m. ¿Qué va a ocurrir con los ejecutivos principales del vendedor?

Si la carta de intenciones hace referencia a que la compra de la compañía se va a realizar a través de un intercambio de acciones, deberá figurar en ella la relación de intercambio de títulos, lo que normalmente se denomina tipo de canje. Esta última se habrá obtenido después de valorar las acciones del comprador y del vendedor, el número de acciones emitidas de ambos, y el número de opciones y warrants emitidos por las dos partes.

El que la carta esté muy detallada, o no, dependerá de lo avanzado de las negociaciones entre las partes y de hasta cuánto deseen moralmente comprometerse. Como hemos señalado en otros apartados de este trabajo, es necesario comprender que, a pesar de sus limitaciones, la carta de intenciones puede ser interpretada como un acuerdo que compromete legalmente a las partes, por lo que es aconsejable la inclusión de cláusulas que excluyan claramente su carácter obligatorio y clarifiquen expresamente que se trata simplemente de una primera invitación a negociar y que puede servir para clarificar la interpretación del futuro contrato en el caso de que llegue a celebrarse, pero que de forma alguna puede considerarse como contrato entre las partes. Además, resulta aconsejable que las cartas de intenciones no estén tan detalladas como para incluir todos los posibles elementos del futuro contrato. En caso contrario, y en el supuesto de que surja el litigio entre las partes, los Tribunales pueden llegar a considerar que la calificación como simple carta de intenciones de los acuerdos entre las partes resulta indiferente, habiendo surgido entre ellas una verdadera obligación de concluir la negociación iniciada cuando una de ellas confía legítimamente y de buena fe en dicha conclusión, surgiendo, además, en ocasiones, una verdadera obligación de indemnizar con base en el genérico principio de "neminem laedere".

\section{CONCLUSIONES}

La empresa, en cuanto a la realidad compleja que opera en el tráfico jurídico económico, presenta una serie de peculiaridades de las cuales no es la menos importante la de que, siendo susceptible de ser objeto de los más variados negocios 
jurídicos, es, o puede ser, al mismo tiempo, sujeto de esos negocios. De esta manera la empresa, en cuanto que identificada con un empresario individual o social, puede comprar, vender, arrendar o celebrar cualquier tipo de contrato en el tráfico económico.

A todo negocio ha de serle atribuido un sentido, de manera que todas las declaraciones de voluntad, tanto las que ofrecen un sentido claro (si bien en menor medida) como las que tienen un sentido dudoso, exigen y presuponen la función interpretativa ${ }^{38}$.

En el caso de los contratos celebrados por la empresa la interpretación presenta dificultades añadidas, en cuanto el consentimiento para obligarse es prestado por un "ente" respecto del cual resulta difícil afirmar que tenga una voluntad propia, voluntad ${ }^{39}$ que, por otro lado, y de conformidad con los primeros criterios interpretativos que se establecen en el Código Civil, es esencial para determinar cuál es el sentido del negocio jurídico en general y del contrato en particular, así como para decidir cuáles son aquellos casos sobre los que los interesados "se propusieron contratar". Por otro lado, si bien el Código Civil establece que para juzgar cuál sea la intención de los contratantes debe atenderse a sus actos, en el caso de la empresa dichos actos pueden obedecer a distintas políticas empresariales, cambiantes en el tiempo según las coyunturas económicas. Dichas políticas empresariales no pueden, precisamente por esa variabilidad, influir en una labor de interpretación, si ésta quiere ser mínimamente rigurosa. De no ser así, resultaría evidente la inseguridad jurídica generada por un contrato que, según la coyuntura económica, podría ser interpretado en un sentido o en otro.

Resumido lo expuesto, si bien los anteriores criterios interpretativos no agotan los que establece el Código Civil, los problemas apuntados hacen que la interpretación de los contratos celebrados por la empresa presente dificultades añadidas respecto de los celebrados, por ejemplo, por personas físicas. Ello hace que, en este caso concreto sea necesario acudir a criterios adicionales para llevar a cabo una adecuada labor interpretativa.

La necesidad de evitar incertidumbres en la contratación mercantil, así como la agilidad y rapidez que debe presidir el tráfico jurídico mercantil, una de cuyas consecuencias es la de no tener que interrumpir la ejecución de un contrato cada vez que puedan surgir dudas sobre su interpretación, han hecho que se hayan articulado distintas soluciones para intentar prever desde un principio todos los posibles problemas que se pueden plantear en la ejecución de un contrato mercantil y arbitrar las posibles soluciones. La más importante de esas soluciones recibe el nombre de "carta de intenciones".

38 Castán Tobeñas, J. Derecho Civil Español, Común y Foral, Tomo I, Introducción y Parte General, Vol. II, Teoría de la relación jurídica, págs. 880 y ss.

39 O intención según el tenor literal del CC. 
La carta de intenciones es, dicho de la manera más breve posible, el primer documento de una negociación, en el cual una de las partes realiza una invitación a contratar, identifica el objeto de la negociación y los puntos principales sobre los que debe versar aquélla. Dicha identificación opera en un doble sentido, puesto que delimita el objeto inicial de la negociación pero, desde un punto de vista negativo, impide que los pasos intermedios sean considerados como acuerdos contractuales, tanto por el hecho de que en la carta de intenciones se fijan los puntos mínimos sobre los que debe existir un acuerdo, con lo que, de no llegarse a realizar sobre todos ellos no se generará ningún tipo de vínculo obligatorio, como porque la propia carta de intenciones, al establecer normalmente contradeclaraciones, reservas y demás, excluye su fuerza obligatoria. Por otro lado, la propia carta de intenciones al establecer límites, al fijar claramente aquello sobre lo que se quiere negociar, al identificar los extremos mínimos de la negociación, señala cuál es la voluntad negocial que, como vemos al principio de este apartado, opera como criterio interpretativo al revelar la voluntad de una o de las dos partes y el propósito de ellas al contratar.

Lo anterior pone de relieve la importancia de la carta de intenciones, no sólo como soporte a la interpretación del contrato en caso de que surgieran discrepancias sobre el mismo durante su ejecución, sino como medio para otorgar seguridad jurídica a la contratación con empresas, a través de la delimitación inicial de aquello sobre lo que las partes se proponen contratar.

\section{REFERENCIAS}

Alguer, J., (1935) "Para la crítica del concepto de precontrato", Revista de Derecho Privado.

Albaladejo, M., (1985) Derecho Civil; Introducción y Parte General; Volumen II: la relación, las cosas y los hechos jurídicos. Librería Bosch, Barcelona.

Alonso Pérez, M., (1971) “La responsabilidad precontractual”, Revista Jurídica de Cataluña.

Álvarez Arjona, José Ma. y Carrasco Perera., Ángel (Directores). (2001) AAVV. Régimen Jurídico de las Adquisiciones de Empresas, Gómez Acebo \& Pombo, Abogados, Editorial Aranzadi SA. Navarra.

Bercovitz Rodríguez-Cano, A., (2003) Apuntes de Derecho Mercantil, Thomson Aranzadi, Editorial Aranzadi.

Broseta Pont, M., (1983) Manual de Derecho Mercantil, Editorial Tecnos S.A., Madrid.

Castán Tobeñas, J., (1987) Derecho Civil Español, Común y Foral; Tomo Primero; Introducción y Parte General; Vol. II Teoría de la Relación Jurídica, Editorial Reus S.A. Madrid. 
De Los Mozos, J.L., (1965) El principio de la buena fe, sus aplicaciones prácticas en el Derecho civil español, Barcelona.

Díez Picazo, L., (2002) Roca Trías, E., Morales, A.M, Los principios del Derecho Europeo de Contratos, Editorial Civitas, Madrid.

Hernando Cebriá, L., (2002) La empresa como objeto de negocios jurídicos (Un estudio a partir de la Jurisprudencia del Tribunal Supremo), Tirant Monografías, Editorial Tirant Lo Blanch, Valencia.

Jiménez Sánchez, G., (2000) Derecho Mercantil, Editorial Ariel Derecho S.A., Barcelona.

JORDANO BAREA., (1988) "La interpretación de los contratos", Academia Sevillana del Notariado, Madrid.

Lake, R.B. y Draeta, U., (2006) Letters of intent and other precontractual documents. Comparative analysis and forms. Dutterworth Legal Publishers.

Llodrá Grimalt, F., (2003) "Letter of intent, carta de intenciones, precontrato" , Derecho de los Negocios, Madrid.

OMPI., (2007) Organization Mondiale de la Propiete Intellectuel, Understanding Industrial Property.

OMPI., (2007) Organization Mondiale de la Propiete Intellectuel, Understanding Industrial Property.

Puig Brutau, J., (1997) Compendio de Derecho Civil; Vol. II; Derecho de Obligaciones, Contratos y Cuasi Contratos, Obligaciones derivadas de actos ilícitos, $\mathrm{BOSCH}$ Casa Editorial, S.A., Barcelona.

Ragel Sánchez, L., (1997) Manual de Derecho Civil; Derecho de Obligaciones y Contratos, Editorial Librería Técnica Universitaria "Figueroa 2", Cáceres.

Roca Sastre, M., (1948) "El contrato de promesa" en Estudios de Derecho privado.

Román García, A. (1982) El precontrato: estudio dogmático y jurisprudencial Ed. Montecorvo, S.A., Madrid.

Sánchez Román, F., (1899) Estudios de Derecho Civil, IV, Madrid.

Treitel G.H., (1995) The Law of contract, London, $9^{\mathrm{a}}$ Ed.

Vicent Chuliá, F., (2003) Introducción al Derecho Mercantil, Tirant lo Blanch, Valencia. 